Rakenteiden Mekaniikka (Journal of Structural Mechanics)

Vol. 50, No 3, 2017, pp. $201-205$

https://rakenteidenmekaniikka.journal.fi/index

https://doi.org/10.23998/rm.64924

(c) The author(s) 2017.

Open access under CC BY-SA 4.0 license.

\title{
Bayesian sequential experimental design for fatigue tests
}

\author{
Miikka Väntänen ${ }^{1}$, Joona Vaara, Jukka Aho, Jukka Kemppainen and Tero Frondelius
}

Summary. A Bayesian sequential experimental design for fatigue testing based on D-optimality and a non-linear continuous damage model was implemented. The model has two asymptotes for the number of cycles to failure: the fatigue limit and the ultimate tensile strength. With the introduction and stochastic handling of these asymptotes, the D-optimal design accounts naturally for the whole range of reasonable testing levels. Sequential design ensures that all the available data is used efficiently while choosing the next test level.

Key words: Bayesian inference, Bayesian experimental design, Non-linear continuous damage model, hierarchical modeling, Fisher Information

Received 15 June 201\%. Accepted 10 August 2017. Published online 21 August 2017

\section{Introduction}

The fatigue testing has been traditionally divided into testing the SN-curve and the fatigue limit separately. The staircase-test or up-and-down procedure $[3,11]$ has been utilized heavily in finding the fatigue limit median value. The test results have been binary failure or survival. The number of cycles was included in the fatigue analysis in this work. Sequential D-optimal design has been used in this work for choosing the next test level. This way the amount of information from tests is maximized and the precision of further analyses [14, 5, 9] increases in the product design process [7]. Bayesian statistics is seen as a natural tool for this kind of problem providing an easy way of introducing engineering prior knowledge and uncertainty to the mathematical model (see Model section for more). A comprehensive review on Bayesian experimental design is given in [2].

\section{Model}

Fatigue data analysis is based on a non-linear continuous damage (NLCD) model described in [1]. By neglecting the mean stress influence and by integrating the damage from 0 to 1, the simplified version [8] of the SN-curve is as follows:

$$
N_{f}=\frac{\left\langle\sigma_{u}-\sigma_{a}\right\rangle}{\left\langle\sigma_{a}-\sigma_{v}\right\rangle} \cdot\left(\frac{\sigma_{a}}{M}\right)^{-\beta}
$$

\footnotetext{
${ }^{1}$ Corresponding author. miikka.vantanen@gbw.fi
} 
where $N_{f}$ is the number of cycles to failure, $\langle\cdot\rangle$ correspond to Macaulay brackets, $\sigma_{u}$ is the ultimate tensile strength (UTS), $\sigma_{a}$ is the stress amplitude, $\sigma_{v}$ is the fatigue limit, $\beta$ is slope, and $M$ is related to the intercept of the logarithmic SN-curve, respectively.

A stochastic model of (1) can be achieved by defining a random variable $N$ for the number of cycles to failure

$$
\ln N \sim \mathcal{N}\left(\ln N_{f}\left(\sigma_{a} \mid \theta\right), \sigma\right),
$$

where $z \sim \mathcal{N}(\mu, \sigma)$ denotes that $z$ follows a normal distribution with the parameters $(\mu, \sigma), \theta$ is a parameter vector and, here, $\sigma$ is the standard deviation. With the notation $N_{f}\left(\sigma_{a} \mid \theta\right)$ we intend to emphasize that the stress amplitude $\sigma_{a}$ is the input parameter for the mean value of number of cycles to failure. The equation (2) describes the fatigue life with a given UTS and fatigue limit. The model has two asymptotes $\sigma_{a} \rightarrow \sigma_{v}+$ and $\sigma_{a} \rightarrow \sigma_{u}-$. Traditionally these variables are considered stochastic as well

$$
\begin{aligned}
\ln \sigma_{u} & \sim \mathcal{N}\left(\mu_{\ln \sigma_{u}}, \sigma_{\ln \sigma_{u}}\right), \\
\ln \sigma_{v} & \sim \mathcal{N}\left(\mu_{\ln \sigma_{v}}, \sigma_{\ln \sigma_{v}}\right),
\end{aligned}
$$

where $\left(\mu_{\ln \sigma_{u}}, \mu_{\ln \sigma_{v}}\right)$ are the mean values and $\left(\sigma_{\ln \sigma_{u}}, \sigma_{\ln \sigma_{v}}\right)$ are the standard deviations of the logarithmic UTS and fatigue limit, respectively. The joint probability is achieved by marginalization as demonstrated in [12] for the Random Fatigue-Limit Model [10].

An Bayesian approach (see e.g. [6]) was adopted for solving the inference problem. The benefit of this approach is being able to include prior knowledge of the parameters. In this case, e.g. the lower limit of UTS can be found from standards and textbooks. Objective priors can be used for the parameters with uncertainty so the parameter posteriors follow data likelihood more closely. Another advantage of Bayesian approach is the ease of including uncertainty in the parameter approximation and uncertainty due to sample size in the prediction. To avoid computationally heavy marginalization of (3) and (4), hierarchical modeling [6] in statistical programming language Stan [13] was used.

\section{Bayesian sequential experimental design}

The optimal design criteria used here are based on measures taken from the Fisher Information Matrix (see e.g. [4])

$$
\mathcal{I}(x, \theta)=\mathbf{E}_{y}\left[\left(\frac{\partial \log f(y \mid x, \theta)}{\partial \theta}\right)\left(\frac{\partial \log f(y \mid x, \theta)}{\partial \theta}\right)^{\mathrm{T}} \mid \theta\right]
$$

where $\frac{\partial F}{\partial \theta}$ is the gradient of $F$ with respect to the parameter vector $\theta, x$ is the design (stress amplitude), $y$ is a future observation (number of cycles to failure or number of cycles at test stop) over which the expected value is calculated and $f(y \mid x, \theta)$ is the likelihood of observing $y$, given design $x$ and parameters $\theta$. Equation (5) is typically used with Maximum Likelihood Estimate (MLE) but as in the Bayesian framework the posterior distribution $f(\theta \mid \hat{y})$ gives the possibility to avoid choosing point estimates. Instead one can calculate an expected value over the parameter space and also yield the expected Fisher Information Matrix (FIM) as a function of design, having observed data $\hat{y}$,

$$
\mathcal{I}(x \mid \hat{y}):=\mathbf{E}_{\theta \mid \hat{y}} \mathcal{I}(x, \theta),
$$

where we have interpreted $\theta$ as a random variable having the density $f(\theta \mid \hat{y})$. 


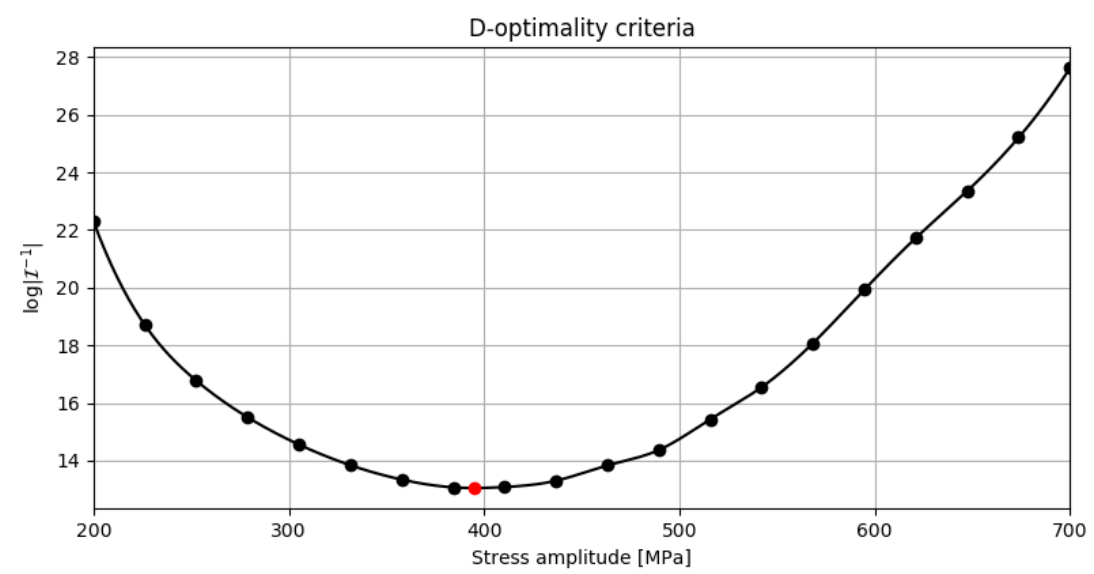

Figure 1. Example of D-optimality minimization objective function.

A popular optimality criterion is the D-optimality which, in our case, maximizes the determinant of the expected FIM $\mathcal{I}(x \mid \hat{y})$ or equivalently minimizes the determinant of the inverse of $\mathcal{I}(x \mid \hat{y})$, whence the D-optimal design $\tilde{x}$ is given by

$$
\tilde{x}=\arg \min _{x}\left|\mathcal{I}(x \mid \hat{y})^{-1}\right| .
$$

The D-optimality is used when the inference about the parameters is the main goal of the analysis [2] and choosing D-optimal design minimizes the volume of a frequentist joint confidence region for the parameter vector [12]. An example result of the optimization problem (7) as a function of the design $x$ as well as the optimal design $\tilde{x}$ are visualized in Figure 1.

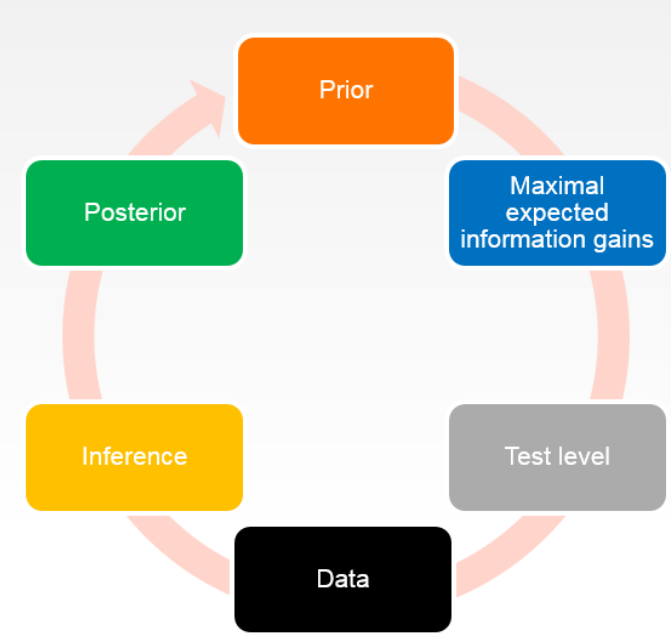

Figure 2. Bayesian sequential experimental design.

The shape of the D-optimality objective function with a local minima between the physical limits is due to the asymptotes in the model (1). Additionally, the developed framework enables dynamically to vary the runout limit (pre-defined number of cycles where the test is stopped if no failure has occured) and see how big of an effect it would have on the D-optimality. 
This is performed in a sequential manner after every test result (observation) so that all information available is used in deciding the new test level in an optimal manner as shown in Figure 2.

\section{References}

[1] J. L. Chaboche and P. M. Lesne. A non-linear continuous fatigue damage model. Fatigue $\&$ Fracture of Engineering Materials $\&$ Structures, 11(1):1-17, 1988. ISSN 1460-2695. URL https://doi.org/10.1111/j.1460-2695.1988.tb01216.x.

[2] Kathryn Chaloner and Isabella Verdinelli. Bayesian experimental design: A review. Statistical Science, pages 273-304, 1995.

[3] W. J. Dixon. The up-and-down method for small samples. American Statistical Association Journal, 60(312):967-978, 1965. URL https://doi.org/10.2307/2283398.

[4] B Roy Frieden. Science from Fisher information: a unification. Cambridge University Press, 2004.

[5] Tero Frondelius, Pasi Halla-aho, and Antti Mäntylä. Crankshaft development with virtual engine modelling. In CIMAC Congress Helsinki, 2016.

[6] Andrew Gelman, John B Carlin, Hal S Stern, and Donald B Rubin. Bayesian data analysis, volume 2. Chapman \& Hall/CRC Boca Raton, FL, USA, 2014.

[7] Juho Könnö, Hannu Tienhaara, and Tero Frondelius. Wärtsilä digital design platform. Rakenteiden Mekaniikka, 50(3):234-238, 2017. URL https://doi.org/10. $23998 / \mathrm{rm} .64621$.

[8] Asko Kumpula, Joona Vaara, Anton Leppänen, and Tero Frondelius. Nodular cast iron ONERA fatigue model fitting. Rakenteiden Mekaniikka, 50(3):179-181, 2017. URL https://doi.org/10.23998/rm.64740.

[9] Anton Leppänen, Asko Kumpula, Joona Vaara, Massimo Cattarinussi, Juho Könnö, and Tero Frondelius. Thermomechanical fatigue analysis of cylinder head. Rakente $i$ den Mekaniikka, 50(3):182-185, 2017. URL https://doi.org/10.23998/rm.64743.

[10] Francis G Pascual and William Q Meeker. Estimating fatigue curves with the random fatigue-limit model. Technometrics, 41(4):277-289, 1999.

[11] Roger Rabb. Todennäköisyysteoriaan pohjautuva väsymisanalyysi. ISBN: 978-952286-210-5. Books on demand. pages 308-309, 2013. ISSN ISBN: 978-952-286-210-5.

[12] Kenneth J Ryan. Estimating expected information gains for experimental designs with application to the random fatigue-limit model. Journal of Computational and Graphical Statistics, 12(3):585-603, 2003.

[13] Stan Development Team. PyStan: the Python interface to Stan, 2016. URL http: //mc-stan.org/. Version 2.15.0.0.

[14] Ilkka Väisänen, Antti Mäntylä, Antti Korpela, Teemu Kuivaniemi, and Tero Frondelius. Medium speed engine crankshaft analysis. Rakenteiden Mekaniikka, 50(3): 341-344, 2017. URL https://doi.org/10.23998/rm.64916. 
Miikka Väntänen, Jukka Aho

Global Boiler Works Oy

Lumijoentie 8

90400 Oulu

miikka.vantanen@gbw.fi, jukka.aho@gbw.fi

Joona Vaara, Tero Frondelius

Wärtsilä

Järvikatu 2-4

65100 Vaasa

joona.vaara@wartsila.com, tero.frondelius@wartsila.com

Jukka Kemppainen

University of Oulu, Applied and Computational Mathematics

Pentti Kaiteran katu 1

90014 Oulu

jukka.t.kemppainen@oulu.fi 